\title{
A multi-compartmented glacial refugium in the northern Rocky Mountains: Evidence from the phylogeography of Cardamine constancei (Brassicaceae)
}

\author{
Steven J. Brunsfeld ${ }^{1, *}$ \& Jack Sullivan ${ }^{2}$ \\ ${ }^{1}$ College of Natural Resources, University of Idaho, Moscow, ID, 83844-1133, USA; ${ }^{2}$ Department of Biology, \\ University of Idaho, Moscow, ID, 83844-3051, USA (*Corresponding author: Phone: + 1-208-885-7211; \\ Fax:+1-208-885-6226; E-mail: sbruns@uidaho.edu)
}

Received 24 August 2005; accepted 30 August 2005

Key words: biodiversity, Cardamine, glacial refugium, phylogeography, Rocky Mountains

\begin{abstract}
The age and origin of the mesic coniferous forest ecosystem of the Pacific Northwest of North America have long been the subject of debate by biogeographers. Cardamine constancei, an endemic of the Rocky Mountain segment of this ecosystem, was subjected to phylogeographic analysis to test explicit hypotheses on the age of the ecosystem. We have predicted genetic homogeneity among river drainages if $C$. constancei and other associated species migrated into the region after glaciation, in contrast to the genetic differentiation that may have accrued if the species and its ecosystem have long survived in the relatively warm river canyons south of glaciation. We detected 19 haplotypes with divergence up to $1.5 \%$, and they comprise 4 well-differentiated cpDNA clades. These clades are allopatric except for two haplotypes from the lower Clearwater clade that appear to have dispersed north into partial sympatry with the clade endemic to St. Joe River. The divergence and distribution of these clades is consistent with the existence of a complex glacial refugium with at least four compartments. The surprisingly high cpDNA diversity within this species suggests that conservation of mesic coniferous forest ecosystems in the region warrant a conservation plan that accounts for the historically imposed spatial structure of genetic diversity. We are currently testing our phylogeographic hypotheses by the comparative analyses of a suite of plants, animals and fungi.
\end{abstract}

\section{Introduction}

Ecosystems have a genetic architecture that is an emergent property of the genetic structure of numerous co-occurring species. Each species has undergone processes such as vicariance, dispersal, population bottlenecks, etc., as a result of historical changes in the environment, including orogeny, volcanism, soil genesis, and climatic events such as glaciation. Some ecosystems currently span geographic regions that have differed greatly in the environmental upheavals that have occurred, resulting in great spatial differences in genetic architecture and species diversity (Demesure et al.1996; Soltis et al. 1997; Avise 2000; Taberlet and Cheddadi 2002; Calsbeek et al. 2003).
Pleistocene glaciation has commonly been considered a powerful force in biotic history, and the existence of glacial refugia has impacted both species and ecosystems (e.g., Ferris et al. 1998; Hewitt 2000; Weider and Hobæk 2003). By testing hypotheses of the genetic structure expected in populations that may have survived in refugia or may have undergone recent dispersal, we can build an understanding of the history of the ecosystem, and provide a foundation for the conservation of cryptic biodiversity and the management of forest resources.

The Pacific Northwest of North America has the greatest extent of mesic coniferous forest in the world (Franklin and Dyrness 1973). This ecosystem, dominated late in succession by Thuja plicata 
(western redcedar) and Tsuga heterophylla (western hemlock), is divided into separate western and eastern segments. The cascadian and coastal forests are separated from those in the northern Rocky Mountains (nRM) to the east by a broad extent of steppe vegetation that occurs in the rainshadow of the Cascade Range. Numerous species, including plants, animals, and fungi, exhibit a disjunct distribution between the two forest segments (Johnson and Steele 1978). In the inland region, species diversity is particularly high in the Clearwater River drainage, which encompasses a major portion of the mesic coniferous forest south of glaciation in the nRM (Figure 1).

Hypotheses about the age and origin of the disjunction have ranged from a relatively ancient sundering (2-5 mya) of a once continuous forest by the rise of the Cascade Range during the Pliocene (Daubenmire 1975), to the colonization of the Rocky Mountains by mesic forest after glaciation as recently as 2-3000 years ago (Mack et al. 1978). Phylogeographic analyses, which examine the temporal and spatial distribution of gene lineages (Avise 2000), provide a means for testing these hypotheses on the age and origin of the mesic forest ecosystems of the region because each hypothesis makes distinct predictions about the magnitude and structure of genetic diversity (Brunsfeld et al. 2001). Under an Ancient Vicariance hypothesis, long-separated coastal and nRM populations of a species would be expected to be genetically diverged, whereas, under the inland

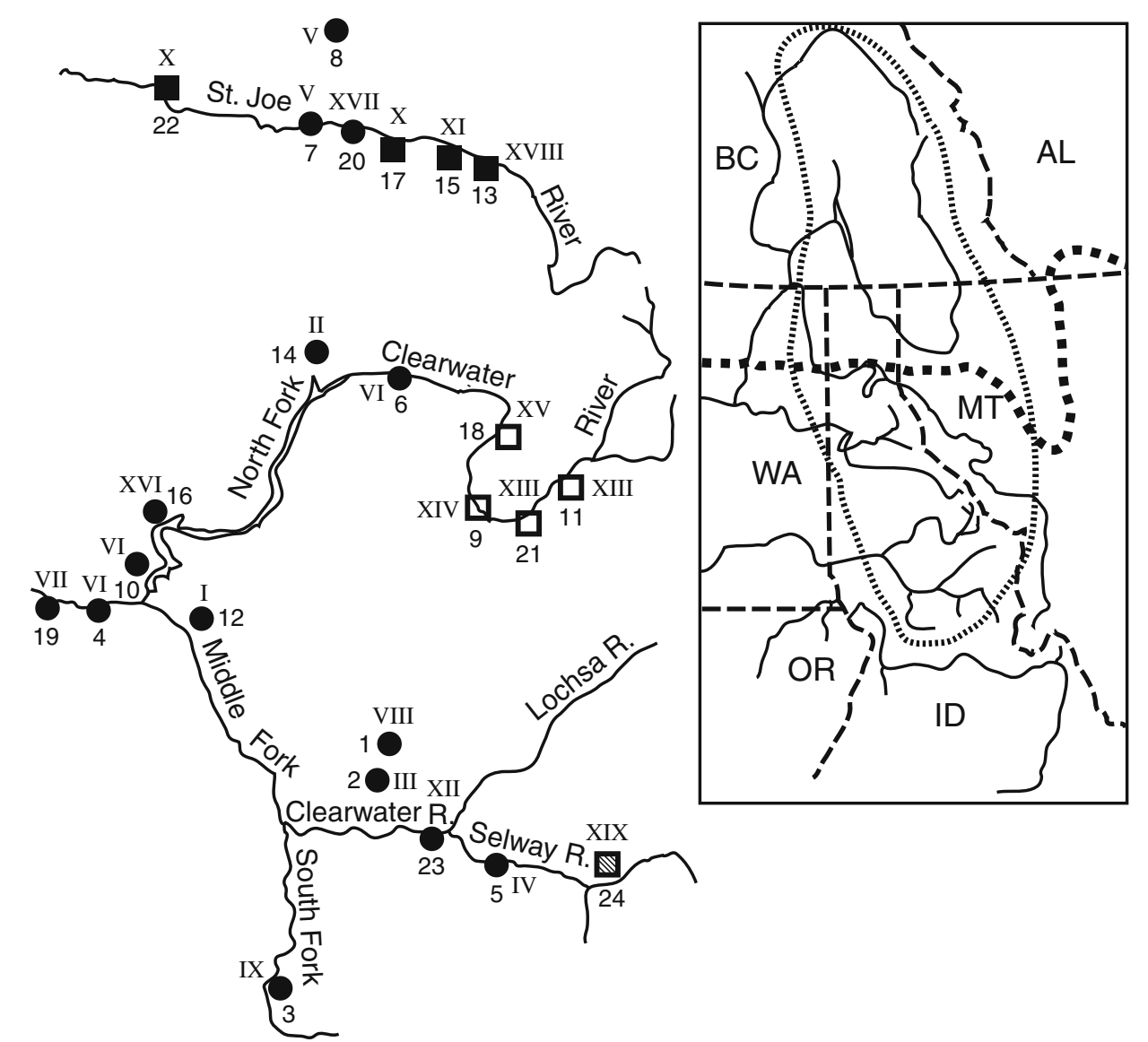

Figure 1. Distribution of Cardamine constancei (left); additional populations are known only between sample localities. Sample location, number, haplotype, and clade membership correspond to information in Table 1 and Figures 2 and 3 . $\bullet=\mathrm{LC}$, $\mathbf{\square}=\mathrm{SJ}$, $\square=\mathrm{NF}$, and $\square=\mathrm{S}$. Inset at right shows location of the Clearwater and St. Joe rivers in the northern Rocky Mountains. Heavy dashed line is the southern limit of Pleistocene glaciation. Fine dashed line is the approximate current distribution of the mesic coniferous forest zone; the southern portion of this zone is the area shown in more detail at left. 
dispersal hypothesis, recent migration into the $\mathrm{nRM}$ would result in a lack of divergence from the coastal source population. Corollary hypotheses include the prediction that if populations survived for long time periods in the separate river canyons of the nRM (as expected under Ancient Vicariance or a RM source of dispersal to the coast), genetic differences might be preserved among separate canyon refugia. In contrast, genetic homogeneity would likely exist among recently colonized drainages.

In this paper we report a phylogeographic analysis of Constance's bittercress (Cardamine constancei Detl., Brassicaceae, a rare rhizomatous herbaceous perennial confined to the understory of $\mathrm{nRM}$ mesic coniferous forests. The species is endemic to the mesic forests in the bottom of river canyons south of the limits of glaciation in the northern Rocky Mountains. Thus, the species would likely have been part of any mesic forest ecosystem that may have survived in isolated river canyons during repeated glacial advances. Because
C. constancei does not occur in the western portions of the ecosysten (i.e., in the Cascades), we use the degree of genetic homogeneity among the nRM drainages to infer the age of the Rocky Mountain segment of Pacific Northwest mesic coniferous forest, and thus whether the region served as a glacial refugium. This work is part of our broader collaboration to use comparative phylogeographic methods to test rigorously the above hypotheses and others related to the history of PNW mesic forest ecosystems.

\section{Methods}

Samples were obtained from 24 localities representing the entire geographic range of the species (Table 1, Figure 1). These included 19 samples collected fresh, and 5 obtained from herbarium specimens. The herbarium specimens represent historical locations that were inaccessible or extirpated (e.g., two populations, \#10 and 16, were

Table 1. Cardamine constancei locations, haplotype and clade designations

\begin{tabular}{|c|c|c|c|c|}
\hline Location & County & Haplotype & Clade & Latitude/Longitude \\
\hline 1. Stray Ck vic. Yakus Ck., M.F. Clearwater R & Idaho Co. & VIII & $\bullet$ & N46.222 W115.740 \\
\hline 2. L. Smith Ck. M.F. Clearwater R. & Idaho Co. & III & $\bullet$ & N46.169 W115.746 \\
\hline 3. SF Clearwater R a(ID 10090) & Idaho Co. & IX & $\bullet$ & N45.959 W115.960 \\
\hline 4. Clearwater R. Hiway 12, mp33 (Baldwin 9611, ID) & Nez Perce Co. & VI & $\bullet$ & N46.498 W116.376 \\
\hline 5. Rackliff Campg. Selway R. & Idaho Co. & IV & $\bullet$ & N46.086 W115.494 \\
\hline 6. Isabella Ck. NF Clearwater R. & Clearwater Co. & VI & $\bullet$ & N46.849 W115.632 \\
\hline 7. Big Ck. St. Joe R. (Baldwin 9618-2, ID) & Shoshone Co. & $\mathrm{V}$ & $\bullet$ & N47.277 W116.114 \\
\hline 8. Jackass Ck. SF Coeur d'Alene R. & Shoshone Co. & $\mathrm{V}$ & $\bullet$ & N47.553 W116.129 \\
\hline 9. Washington $\mathrm{Ck}$ NF Clearwater R. & Clearwater Co. & XIV & $\square$ & N46.703 W115.556 \\
\hline 10. Freeman Ck., NF Clearwater R. '(IDF 6952) & Clearwater Co. & VI & $\bullet$ & N46.566 W116.287 \\
\hline 11. Gilfillian Ck., NF Clearwater R. & Clearwater Co. & XIII & $\square$ & N46.716 W115.314 \\
\hline 12. Clearwater R. US Hiway 12, vic. Mp46 & Clearwater Co. & I & $\bullet$ & N46.491 W116.251 \\
\hline 13. Italian Ck, St. Joe River (Baldwin 9618-3, ID) & Shoshone Co. & XVIII & $\mathbf{\square}$ & N47.254 W115.926 \\
\hline 14. L. North Fork Clearwater R. a(IDF 7024) & Clearwater Co. & II & $\bullet$ & N46.891 W115.872 \\
\hline 15. Slate Ck., St. Joe R. & Shoshone Co. & $\mathrm{XI}$ & $\mathbf{\square}$ & N47.259 W115.938 \\
\hline 16. Dicks Ck., NF Clearwater R. a'(IDF 6970) & Clearwater Co. & XVI & $\bullet$ & N46.618 W116.301 \\
\hline 17. Blackjack Ck, St. Joe R. (Baldwin 9618-4, ID) & Shoshone Co. & $\mathrm{X}$ & $\mathbf{\square}$ & N47.252 W115.984 \\
\hline 18. Moscow Bar, NF Clearwater R. ${ }^{a}$ (IDF 7034) & Clearwater Co. & $\mathrm{XV}$ & $\square$ & N46.791 W115.463 \\
\hline 19. Peck, MF Clearwater R. & Nez Perce Co. & VII & $\bullet$ & N46.498 W116.444 \\
\hline 20. Marble Ck., St. Joe R. & Shoshone Co. & XVII & $\bullet$ & N47.240 W116.006 \\
\hline 21. Cub Ck., NF Clearwater R. & Clearwater Co. & XIII & $\square$ & N46.648 W115.416 \\
\hline 22. Trout Ck., St. Joe R. (Baldwin 9618-1, ID) & Shoshone Co. & $\mathrm{X}$ & $\mathbf{\square}$ & N47.294 W116.256 \\
\hline 23. Two Shadows, Selway R., & Idaho Co. & XII & $\bullet$ & N46.140 W115.666 \\
\hline 24. Selway R. Falls & Idaho Co. & XIX & $Z_{2}$ & N46.044 W115.252 \\
\hline C. pulcherrima (SJB 4049) Douglas Park & Clatsop Co. OR & Outgroup & & \\
\hline
\end{tabular}

\footnotetext{
${ }^{\text {a }}$ DNA sample obtained from herbarium specimen housed in ID or IDF; other vouchers in parentheses.
} 
destroyed by the damming of the North Fork of the Clearwater R.). Cardamine pulcherrima was collected to serve as an outgroup (Table 1). Fresh tissue was transported on ice to the lab for DNA extraction, which followed the modified CTAB method of Brunsfeld et al. (1992).

\section{Molecular data collection}

Three portions of the chloroplast genome were amplified using the polymerase chain reaction (PCR) from at least one plant from each locality. PCR mixtures totalling $25 \mu \mathrm{l}$ contained $10 \mathrm{mM}$ Tris- $\mathrm{HCl}$ ( $\mathrm{pH} 8.3$ ), $50 \mathrm{mM} \mathrm{KCl}, 2 \mathrm{mM} \mathrm{MgCl}$, $1 \%$ Tritron X-100, $0.25 \mu \mathrm{g}$ BSA, $0.2 \mathrm{mM}$ of each dNTP, $5 \mathrm{pM}$ of primer, $10 \mathrm{ng}$ of DNA, and 0.5 units of Taq DNA polymerase (Promega), overlayed with $25 \mu \mathrm{l}$ of mineral oil. The PCR products included: (1) 693 bases spanning the $3^{\prime}$ end of $m a t \mathrm{~K}$ to $3^{\prime} \operatorname{trn} \mathrm{K}\left(\operatorname{trn} \mathrm{K} 2 \mathrm{R}-5^{\prime}\right.$-ACCTAGTCGGATGGAGTAG and matK1800 F - 5'-TCAA GGGTACGTAGTCAAATG); (2) 588 bases of the spacer between $\operatorname{trn} \mathrm{L}(\mathrm{UAA})$ and $\operatorname{trn} \mathrm{F}(\mathrm{GAA})-$ primer " $\mathrm{e}$ " to " $\mathrm{f}$ " sensu Taberlet et al. 1991, and (3) a 394 base spacer in the small single copy region (ndh $\mathrm{G} \mathrm{F}$ - 5'-AAGTAATACCACTCCTAGACCCCC to $n d h \mathrm{I} \mathrm{R}-5^{\prime}$-CAATGACCGAAGA ATATGAACTTT). The products were treated with ExoSapIT (Amersham). Cycle sequencing with dye-labeled primers was conducted following manufacturers specifications: SequiTherm EXCEL (Epicentre) for LI-COR 4000L sequencing, and Big Dye (Applied Biosystems) for ABI 377 sequencing. Sequencing reactions were cleaned on sephadex columns before electrophoresis. Alignment was initially approximated with Clustal W 1.8 (BCM Search Launcher http://dot.imgen. $\mathrm{bcm} . \mathrm{tmc} . \mathrm{edu})$ and finalized by eye.

\section{Data analysis}

We estimated the phylogeny of chloroplast DNA sequences using maximum likelihood, as implemented by PAUP* ver. 4.0 beta (Swofford 2002), and used the approach to model selection illustrated by Swofford and Sullivan (2003). This approach involves evaluating a set of nested models of sequence evolution, seeking the model that optimizes the tradeoff between fit and parameter economization given a preliminary tree that is held constant. The initial tree was produced using neighbor joining on logdet distances in PAUP and this tree was used to simplify the most parameterrich $\mathrm{GTR}+\mathrm{I}+\Gamma$ model using a dynamic topdown approach (Swofford and Sullivan 2003). The model selected (with parameters fixed) was then used to conduct a heuristic search with TBR branch-swapping and the "MulTrees" option.

Nodal support was estimated via bootstrap analysis (Felsenstein 1985) with 100 replicates. Nodal posterior probabilities were estimated by Bayesian analysis (MrBayes ver.3.0, Huelsenbeck and Ronquist 2001). We ran four chains of one million generations with uniform priors, sampling every 100 generations, with the first 10,000 generations discarded as the burn-in. We conducted four independent runs starting with different random trees, and assessed stationarity of MCMC specifically with respect to topology following Carstens et al. (2004).

Because divergence times and migration are important to the interpretation of our cpDNA data, we used MDIV (Nielson and Wakeley 2001) to jointly estimate these parameters in a comparison between two populations. The two populations were the lower Clearwater valley, including all 11 plants sampled there, and the St. Joe River, including all 7 collected there. These sets of localities were selected a posterior, following the results of the phylogenetics analysis (see Carstens et al. 2005); the diverged sequences from the North Fork and Selway River valleys were not included. We conducted several iterations of the analysis using a finite sites model (e.g., HKY), and starting with a default of $M=10$ and $T=5$, and, based on these results, subsequently used prior values of $M=5$ and $T=2$. This iterative adjustment of priors follows the recommendations of Nielson and Wakeley (2001). Three Markov chains of $2 \times 10^{6}$ generations were repeated to assess stationarity.

To provide a complementary perspective on microevolutionary patterns and population history we conducted a Nested Clade Analysis (NCA) following the general methods of Templeton et al. (1987) and Templeton $(1998,2004)$. This method uses evolutionary relationships, inferred from a nested haplotype tree, and geographic distributions of clades to explore statistically significant associations of haplotypes with geography (Templeton et al. 1995, Templeton 1998). The number of mutational differences between haplotypes for 
which parsimonious connections have a probability of at least 95\% (Templeton et al. 1992) was first calculated using TCS (ver. 1.06, Clement et al. 2000). Unique haplotypes were next assembled into a network founded on the number of mutational steps separating each pair of haplotypes. The resulting "n-step clades" were arranged hierarchically as illustrated by Templeton et al. (1987). The analysis performed by GEODIS (2.0, Posada et al. 2000) uses 10,000 permutations to test the null hypothesis that there is no association between clade relationships and the geographic patterns (Templeton et al. 1995). Other procedures and the theoretical basis of NCA analysis have already been described in detail (e.g., Templeton et al. 1987, 1995; Templeton 1998, 2004).

\section{Results}

The three chloroplast DNA segments were combined into a single matrix of 1690 characters. Of 24 samples sequenced, 19 unique haplotypes (excluding the outgroup) were detected. Each collection site appeared in the field to consist of a single rhizomatous clone. To test the clonality of plants at a site, we chose one location and sequenced diagnostic portions of five samples. All were identical, so we did not sequence multiple plants from apparent clones at other locations. DNA sequences for each of the three chloroplast regions and for each major lineage are deposited in GenBank (matK-trnK, AY994188-91; trnL-trnF, DQ001140-3; ndhG-ndhI, DQ004466-9). Uncorrected sequence divergence was up to $1.5 \%$, excluding insertions and deletions. The model we selected is a special case of the GTR $+\mathrm{I}+\Gamma$ model with three substitution types defined by rclas$\mathrm{s}=($ aabcaa $)$, invariable sites, and a $\Gamma$ distribution for variable sites. This yielded a tree with a score of $-\ln \mathrm{L}=2798.07$ (Figure 2). The Bayesian analysis yielded a consensus tree with a topology identical to the ML tree (Figure 2), at least with regard to the branches with $>50 \%$ support. As is commonly the case, nodal posterior probabilities were generally higher than ML bootstrap values.

All analyses yielded two major clades (Figure 2). One, consisting of $12 \mathrm{cp}$ haplotypes, is poorly supported (ML and Bayesian, 51 and 65\%, respectively), and is centered in the lower Clearwater R. (the "LC" clade). Three populations from the St. Joe and Coeur d'Alene River drainages also belong to this clade. The second major clade is very well supported (100/99\%) and largely an upstream entity (the "US" clade). It consists of three strongly differentiated lineages: (1) the "NF" clade $(100 / 100 \%)$ includes three haplotypes found in four populations in the upper North Fork of the Clearwater R., (2) the "S" clade, contains one haplotype from the upper Selway River, and (3) the "SJ" clade $(54 / 83 \%)$ from the St. Joe River, containing three haplotypes sampled at four sites. The NF and $\mathrm{S}$ clades are sisters with strong nodal support $(89 / 100 \%)$.

The MDIV analysis yielded the following estimates (Table 2: Theta $(\Theta)=4.9 \quad(3.28-10.4)$, $M=0.21(0.5-2.78)$, and $T=0.75$ (lower bound $=$ $0.32)$. Theta was used to calculate $N_{e}$ for mutation rates ranging from $\mathrm{u}=10^{-6}$ to $10^{-9}\left(N_{e}=\Theta / 2 \mathrm{u}\right)$. Finally, divergence times were calculated for each mutation rate using the lower bound of $T$ and $N_{e}$, and a generation time of 5 years $\left(T_{\mathrm{div}}=T / 2 N_{e} / 5\right)$. Divergence time and $N_{e}, 50$ mya and 625 million plants (lower bound estimates), both appear to be unrealistically high for $\mu=10^{-9}$. This is the rate estimated for cpDNA in Brassicaceae (Koch et al. 2001) and plants in general (Wolfe et al. 1987). Fifty mya is older than the time estimated for Rocky Mountain orogeny (see Brunsfeld et al. 2001), and only a few thousand plants currently exist. Because much of our sequence is noncoding spacer cpDNA, a faster rate is plausible. A mutation rate of $\mu=10^{-8}$ yields a divergence time estimate of 5 mya, which is plausible based on the minimum age of the habitat (Carstens et al., 2005). The effective population size estimated from this mutation rate is 62.5 million plants. This value is also problematic, but larger populations in the past are arguably more likely than faster mutation rates, which yield smaller population estimates. The generation time of Cardamine is also unknown, and may actually differ from our estimate of 5 years. The three samples (haplotypes $\mathrm{V}$ and XVII) from the lower Clearwater lineage occurring in the St. Joe population (Figures 1, 2, and 3) appear to be best explained by recent migration over the low divide that separates the Clearwater and St. Joe drainages. Our MDIV estimate of migration rate $(M=0.21)$ is low, and includes 0 as its lower bound. Nonetheless, the fact that the two haplotypes form a "tip" in the minimum spanning tree of the Clearwater lineage (Figure 3), and are 


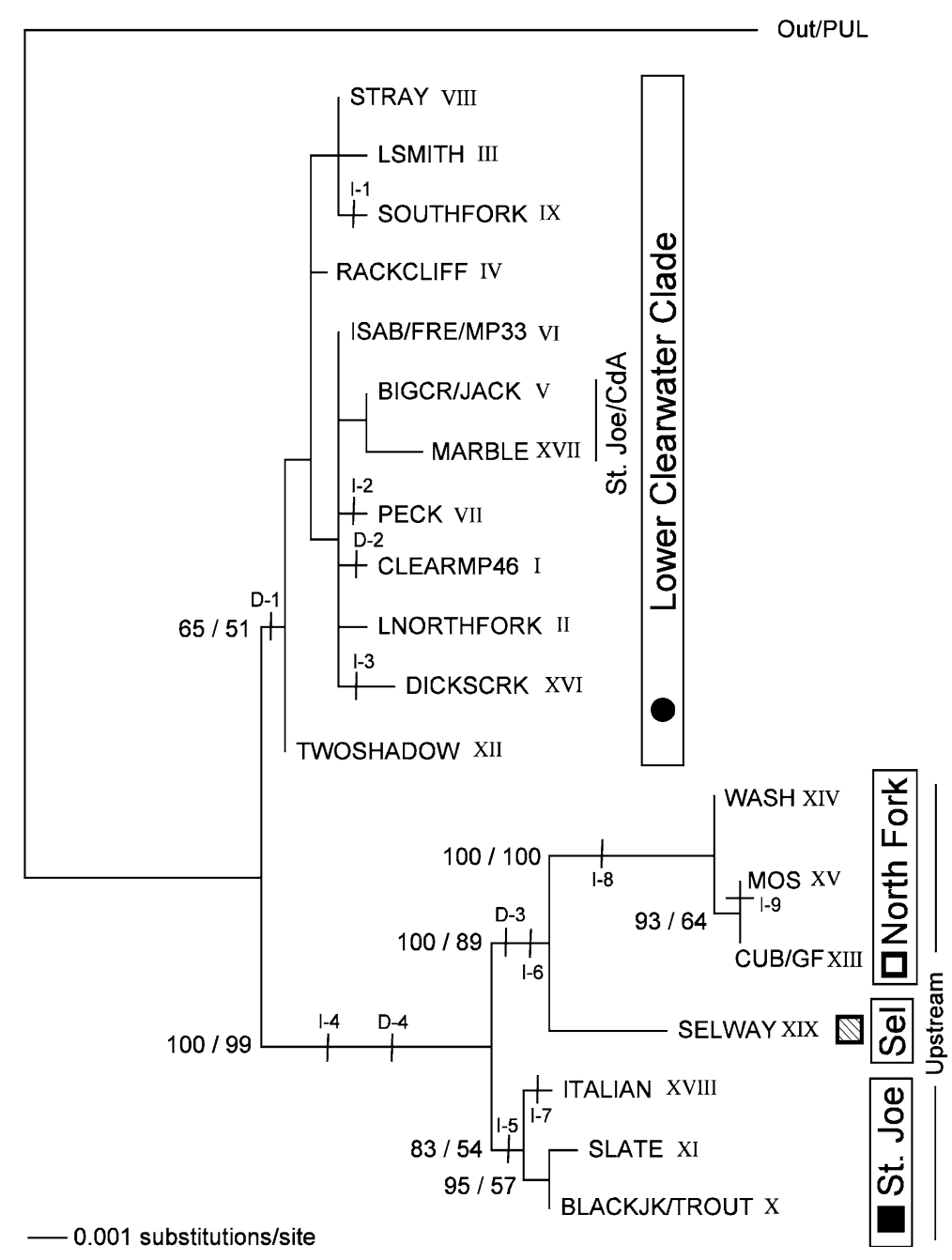

Figure 2. Maximum likelihood analysis of chloroplast DNA sequence for 19 haplotypes of Cardamine constancei. See Table 1 for information on each location, haplotype and clade designation. Numbers on branches are Bayesian posterior probabilities/ML bootstrap percentages. Only values greater than 50\% are shown for each. I-1 through I-9 and D-1 through D-4 are insertions and deletions as inferred from outgroup comparisons, and were mapped onto the ML tree. The size and position of these length mutations on the final sequence alignment are: I-1, 993-1080; I-2, 1526; I-3, 95-103; I-4, 1206-17; I-5, 131-138; I-6, 1526; I-7, 1440-3; I-8, 113842; I-9, 107; D-1, 933-1080; D-2, 91; D-3, 1153-67; D-4, 1648.

highly diverged from the intermingled St. Joe haplotypes, suggest that ancestral polymorphism in the St. Joe drainage is less likely than northward migration over the low divide (see Figure 1).

The haplotype tree generated for the NCA (Figure 3) shows four nested clades (2-1, 2-2, 2-3, 2-4) corresponding to the four lineages (LC, NF, $\mathrm{S}$, and $\mathrm{SJ}$ ) revealed by the phylogenetic analyses. Sixteen steps is the $95 \%$ limit for parsimonious connections, and the shortest connection with LC is to the $\mathrm{SJ}$ clade (11 steps). All other connections to LC (from NF and S) are 17 steps. Relationships among the three US clades are not resolved by the minimum-spanning network; all three being essentially equally diverged (9-10 steps). Thus, relationships are best inferred from the ML tree (Figure 2). The NCA failed to reject the null hypothesis of no geographic structure in any clade, which probably is the result of small sample sizes.

Thirteen length mutations occur in the data matrix: four deletions and nine insertions based on outgroup comparisons. They were treated as missing data in all of our analyses, but seven of these characters support relationships inferred from nucleotide substitution data; two support the 
Table 2. Estimates on earliest plausible divergence times ${ }^{\mathrm{a}}$

\begin{tabular}{llll}
\hline Mutation rate & $N_{e}$ & $\begin{array}{l}\text { Divergence time, assuming 5 year generation } \\
\text { time and lower bound on TDiv }\end{array}$ & $\begin{array}{l}\text { Divergence time, assuming 5 year } \\
\text { generation time and most probable TDiv }\end{array}$ \\
\hline $10^{-5}$ & 245,000 & $9824(5000-20,000)$ & $18,420(9375-375,000)$ \\
$10^{-6}$ & $2,450,000$ & $98,240(50,000-200,000)$ & $184,200(93,750-3,750,000)$ \\
$10^{-7}$ & $24,500,000$ & $982,400(500,000-2,000,000)$ & $1,842,000(937,500-37,500,000)$ \\
$10^{-8}$ & $245,000,000$ & $9,824,000(5,000,000-20,000,000)$ & $18,420,000(9,375,000-375,000,000)$ \\
$10^{-9}$ & $2,450,000,000$ & $98,240,000(50,000,000-200,000,000)$ & $184,200,000(93,750,000-3,750,000,000)$ \\
\hline
\end{tabular}

${ }^{\text {a }}$ Estimate of Theta $\left(=2 N_{e} \mu\right): 4.912$ (95\% credibility interval; 3.28-10.47), Estimate of M: 0.21 (95\% credibility interval; 0.05-2.78), Estimate of TDiv: 0.75 (95\% lower bound; 0.32).

US clade, one is shared by SJ haplotypes, one is shared by NF, and two unite NF and S. Five occurred in a single haplotype. An 88 base deletion occurred in every member of the LC clade except the single historical herbarium sample from the South Fork of the Clearwater R. In exploratory Maximum Parsimony analyses (not shown), in which presence or absence of length mutations were treated as separate binary characters, many equally most-parsimonious trees placed South Fork as the sister to the rest of the LC clade.

\section{Discussion}

The mesic coniferous ecosystem of the northern Rocky Mountains is composed of a complex mixture of species, including wide-ranging taxa, endemics, and disjuncts from the similar ecosystem of the Cascades and coastal mountains. Cardamine constancei is a Rocky Mountain endemic of the non-glaciated part of this ecosystem. It is one of many species (e.g., Collomia heterophylla, Cornus nuttallii, Alnus rubra) whose range does not extend north into the region of Pleistocene glaciation. How these disjunct and endemic species attained their current distribution is a question that has long fascinated biogeographers (Lieberg 1900; Detling 1968; Daubenmire 1975). An overriding question is whether the Rocky Mountain portion of the mesic coniferous ecosystem is a remnant of a formerly continuous community sundered by the rise of the Cascade Range several million years ago. Alternatively, members of the ecosystem may have dispersed into the RM after glaciation (the "Ancient Vicariance" vs. the "Inland Dispersal" hypothesis; Brunsfeld et al. 2001). In the absence of a detailed fossil record, a chronicle of the intraspecific evolutionary history of species can be inferred from the degree and distribution of genetic variation among populations. Such studies, which include our analysis of $C$. constancei, are the focus of the burgeoning field of phylogeography (e.g., Avise 2000). Brunsfeld et al. (2001) reviewed the phylogeogaphic literature of the region, and since that review only a few studies have been published (Demboski and Cook 2001; Good and Sullivan 2001; Wilke and Duncan 2004; Carstens et al. 2005). These recent studies focus primarily on animals and corroborate phylogeographic patterns we previously described. These studies suggest that many taxa have a longer history in the NRM than could be explained by a post-Pleistocene origin of the ecosystem (e.g., water voles, tailed frogs, Idaho giant salamanders, Coeur d'Alene salamanders, and dusky willows; Carstens et al. 2005).

If the Rocky Mountain portion of the mesic coniferous ecosystem is indeed of ancient origin and has survived in a glacial refugium south of the extent of Cordilleran ice sheets (Figure 1), we have hypothesized (Brunsfeld et al. 2001) that populations from separate river canyons within the unglaciated area could exhibit genetic divergence fostered by genetic drift and limited gene flow. This is precisely what we discovered in our analysis of Cardamine cpDNA. We found a wellsupported "upstream" (US) clade, itself consisting of three strongly differentiated groups of populations from the St. Joe, upper North Fork of the Clearwater, and upper Selway Rivers. Furthermore, the "downstream" LC clade, centered in the middle Clearwater River drainage, is largely allopatric, except in the middle St. Joe River where the two major lineages mingle. The minimum spanning network produced for the NCA (Figure 3) shows the ancestral haplotype of the LC clade (VI) to exist in the lower North 


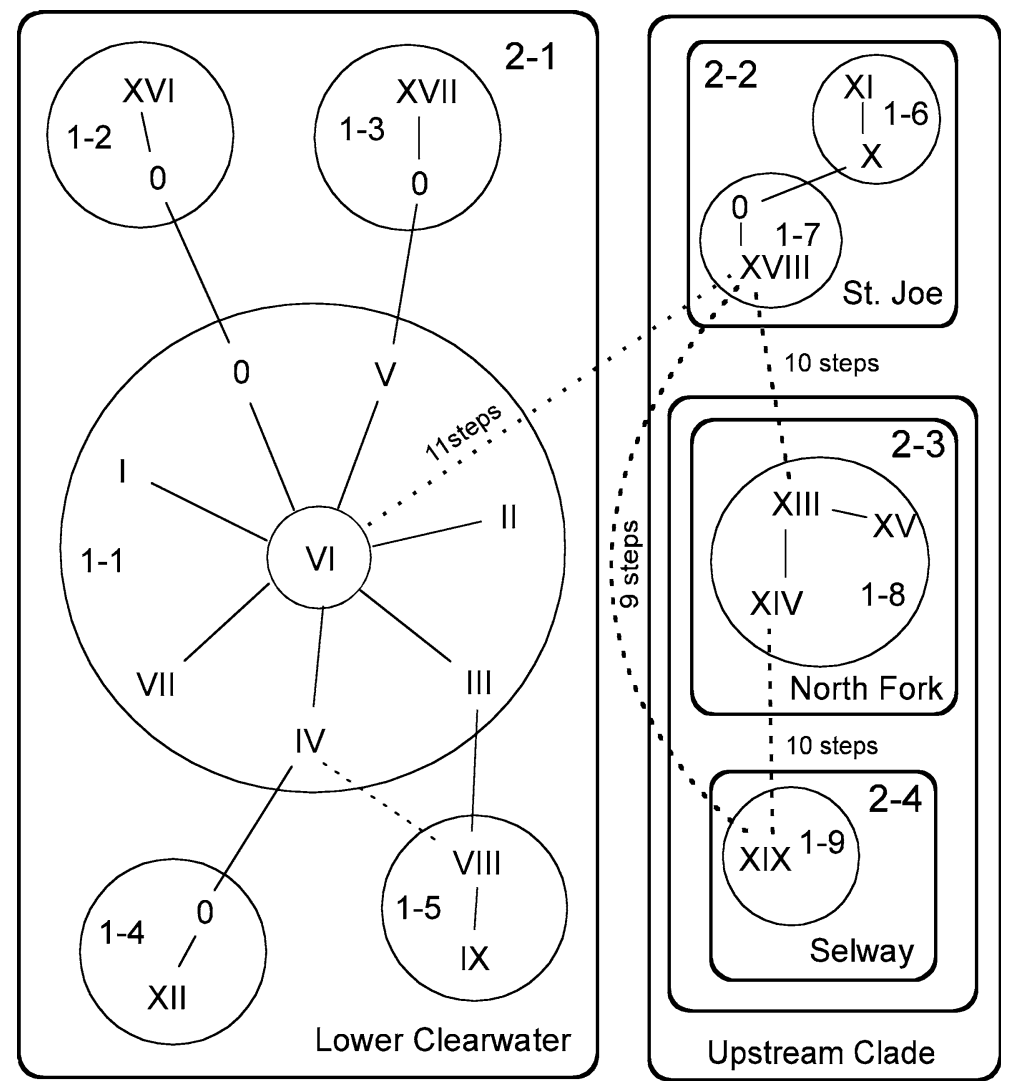

Figure 3. Minimum spanning tree of 19 cpDNA haplotypes of Cardamine constancei."0"s represent unobserved haplotypes. See Table 1 for the identity of each haplotype (Roman numerals). Methods and Results provide more information on this analysis.

Fork and Middle Fork of the Clearwater River (Figure1). Variant LC haplotypes occur throughout this region and into the lower Selway and South Fork of the Clearwater. Two derivatives (V and XVII) of the ancestral LC haplotype appear to have dispersed over the ridge northward into the St. Joe and Coeur D'Alene River drainages. Although concerns have been presented about the inability of NCA to assess error and distinguish among historical processes (Knowles and Maddison 2002), the ambiguity of results in this case appears to be related to small sample sizes. Although the MDIV analysis produced divergent time estimates that were equivocal, times based on the most likely mutation rates indicated an ancient split between populations. This result is consistent with all other data, and raises the question of whether potentially adaptive morphological, phenological and other differences might exist among the geographical regions defined by the cpDNA clades.
The relatively high divergence among the LC and three US clades contrasts strongly with usually low levels of intraspecific cpDNA differentiation in plants (Wolfe et al. 1987). Byrne et al. (1999) compared 13 studies in which intraspecific divergence was measured, and reported a range of values $(0.00-0.15)$ similar to our mean of $0.18 \%$ among haplotypes within major clades. Divergence among the three US clades was five-fold higher $(0.73 \%)$, and between LC and US was ninefold higher $(1.3 \%)$ than average cpDNA divergence values for other taxa (Byrne et al. 1999). These high levels of divergence appear to make post-glacial colonization extremely unlikely. Thus, populations of Cardamine likely survived glaciation and may have been isolated in as many as four separate regions. We consider these to be compartments of a "Greater Clearwater Refugium", and the four compartments of the refugium likely were shifted down-canyon during the height of glaciation, but the full glacial locations of each 
cannot be determined by molecular genetic data (Taberlet et al. 1998). Within the Clearwater drainage, however, a downstream displacement of less than $100 \mathrm{~km}$ would have been necessary to prevent the mingling of the NF and $\mathrm{S}$ haplotypes, which we did not detect.

Because $C$. constancei has a strong affinity for understory habitats in mesic coniferous forests, we predict that similar patterns of inter-drainage divergence will be found in other species of the Clearwater region. There is no reason to believe, however, that all of the members of this ecosystem have a common history (Davis 1983; Delcourt and Delcourt 1987, 1991). Because Constance's bittercress is much more rare than most of its mesic forest associates, analysis of other species might suggest other refugial compartments (e.g., the Lochsa River) that are not currently occupied by C. constancei. Our ongoing multi-kingdom, comparative phylogeography studies should shed additional light on the complex history and structure of this important ecosystem and its species components. Future conservation plans should embrace whole-ecosystem genetic resources, rather than the current single species approach. Comparative phylogeography will help define not only conservation-worthy genetic variation in endemic species, but also will circumscribe regions likely to possess abundant cryptic biodiversity in both common and non-charismatic species. This is particularly critical because genetic studies of other nRM mesic forest endemics (e.g., Plethodon idahoensis, Carstens et al. 2004) also support a compartmentalized Clearwater Refugium.

Ultimately, with the accumulation phylogeographic data from a sufficient number of exemplar members of the ecosystem, managers will be able to circumscribe the boundaries of ecosystems defined by the above process as a layer on their existing GIS-mapped landscape. The new field of "Landscape Genetics" (Manel et al. 2003) is closely related, but tends to focus on population genetics of individual species. Our approach shares many goals with landscape genetics. The integration of comparative phylogeography with GIS makes the evolutionary legacy of the landscape accessible to managers. Even though the genetic patterns may not be evident in the field, incorporation into GIS maps will allow managers to integrate genetic data into their management plans.

\section{References}

Avise JC (2000) Phylogeography: The History and Formation of Species, Harvard University Press, Cambridge, MA.

Brunsfeld SJ, Soltis DE, Soltis PS (1992) Evolutionary patterns and processes in Salix sect. Longifoliae: Evidence from chloroplast DNA. Syst. Bot., 17, 239-256.

Brunsfeld SJ, Sullivan J, Soltis DE, Soltis PS (2001) Comparative phylogeography of Northwestern North America: A synthesis. In: Integrating ecological and evolutionary processes in a spatial context (eds Silvertown J, Antonovics J), pp. 319-339. Blackwell Science, Oxford.

Byrne M, Macdonald B, Coates D (1999) Divergence in the chloroplast genome and nuclear rDNA of the rare Western Australian plant Lambertia orbifolia Gardner (Proteaceae). Mol. Ecol., 8, 1789-1796.

Calsbeek R, Thompson JN, Richardson JE (2003) Patterns of molecular evolution and diversification in a biodiversity hotspot: The California Floristic Province. Mol. Ecol., 12, 1021-1029.

Carstens BC, Stevenson AL, Degenhardt JD, Sullivan J (2004) Testing nested phylogenetic and phylogeographic hypotheses in the Plethodon vandykei species group. Syst. Biol., 53, 781792.

Carstens BC, Demboski JR, Good JM, Brunsfeld SJ, Sullivan J (2005) The evolutionary history of the northern Rocky Mountain mesic forest ecosystem. Evolution, in press.

Clement M, Posada D, Crandall KA (2000) TCS: A computer program to estimate gene genealogies. Mol. Ecol., 9, 16571659.

Daubenmire R (1975) Floristic plant geography of eastern Washington and northern Idaho. J. Biogeogr., 2, 1-18.

Davis MB (1983) Quaternary history of deciduous forests of eastern North America and Europe. Ann. Mo. Bot. Gard., 70, 550-563.

Delcourt PA, Delcourt HR (1987) Long-term forest dynamics of the temperate zone, Springer-Verlag, N.Y.

Delcourt HR, Delcourt PA (1991) Quaternary Ecology, A Paleoecological Perspective, Chapman and Hall, London.

Demboski JR, Cook JA (2001) Phylogeography of the dusky shrew, Sorex monticolus (Insectivora, Soricidae): insight into deep and shallow history in northwestern North America. Mol. Ecol., 10, 1227-1240.

Demesure B, Comps B, Petit RJ (1996) Chloroplast DNA phylogeography of Common Beech (Fagus sylvatica L.) in Europe. Evolution, 50, 2515-2520.

Detling LE (1968) Historical background of the flora of the Pacific Northwest. Bulletin No. 13, Museum of Natural History, University of Oregon, Eugene.

Felsenstein J (1985) Confidence limits on phylogenies: An approach using the bootstrap. Evolution, 39, 783-791.

Ferris C, King RA, Vainola R, Hewitt GM (1998) Chloroplast DNA recognizes three refugial sources of European oaks and suggests independent eastern and western immigrations to Finland. Heredity, 80, 584-593.

Franklin JF, Dyrness CT (1973) Natural Vegetation of Oregon and Washington. General Technical Report PNW-8, USDA Forest Service, Portland, Oregon.

Good JM, Sullivan J (2001) Phylogeography of the red-tailed chipmunk (Tamias ruficaudus), a northern Rocky Mountain endemic. Mol. Ecol., 10, 2683-2695. 
Hewitt GM (2000) The genetic legacy of the quaternary ice ages. Nature, 405, 907-913.

Huelsenbeck JP, Ronquist F (2001) MrBayes: Bayesian inference of phylogenetic trees. Bioinformatics, 17, 754-755.

Johnson FD, Steele R (1978) New plant records from Pacific coastal refugia. Northwest Sci., 52, 205-211.

Knowles LL, Maddison WP (2002) Statistical phylogeography. Mol. Ecol., 11, 2623-2635.

Koch M, Haubold B, Mitchell-Olds (2001) Molecular systematics of the Brassicaceae: Evidence from coding plastidic mat $\mathrm{K}$ and nuclear chs sequences. Am. J. Bot., 88, 534-544.

Leiberg JB (1900) Bitterroot forest reserve. In: Twentieth annual rep. of the U.S. Geol. Survey, Part V-forest reserves, pp. 317-410. Wash. Govern. Print. Off.

Mack RN, Rutter NW, Bryant VM Jr, Valastro S (1978) Late quaternary pollen record from Big Meadow, Pend Oreille County, Washington. Ecology, 59, 956-965.

Manel S, Schwartz MK, Luikart G, Taberlet P (2003) Landscape genetics: Combining landscape ecology and population genetics. Trends Ecol. Evol., 18, 189-197.

Nielson R, Wakeley J (2001) Distinguishing migration from isolation: A Markov Chain Monte Carlo approach. Genetics, 158, 885-896.

Posada D, Crandall KA, Templeton AR (2000) GeoDis, a program for the cladistic nested analysis of the geographical distribution of genetic haplotypes. Mol. Ecol., 9, 487-488.

Soltis DE, Gitzendanner MA, Strenge DD, Soltis PS (1997) Chloroplast DNA intraspecific phylogeography of plants from the Pacific Northwest of North America. Plant Syst. Evol., 206, 353-373.

Swofford DL (2002) PAUP*. Phylogenetic Analysis Using Parsimony (*and Other Methods). Ver. 4. Sinauer Associates, Sunderland, Mass.

Swofford DL, Sullivan J (2003) Phylogeny inference based on parsimony and other methods using PAUP*. In: The Phylogenetic Handbook, A Practical Approach to DNA and Protein Phylogeny (eds Salemi M, Vandamme A-M), pp. 160-206. Cambridge University Press, Cambridge, UK.
Taberlet P, Gielly L, Pautou G, Bouvet J (1991) Universal primers for amplification of three non-coding regions of chloroplast DNA. Pl. Mol. Biol., 17, 1105-1109.

Taberlet P, Fumagalli L, Wust-Saucy A-G, Cosson J-F (1998) Comparative phylogeography and post glacial colonization routes in Europe. Mol. Ecol., 7, 453-464.

Taberlet P, Cheddadi R (2002) Quaternary refugia and persistence of biodiversity. Science, 297, 2009-2010.

Templeton AR (1998) Nested clade analyses of phylogeographic data: Testing hypotheses about gene flow and population history. Mol. Ecol., 7, 381-397.

Templeton AR (2004) Statistical phylogeography: Methods of evaluating and minimizing inference errors. Mol. Ecol., 13, 789-809.

Templeton AR, Boerwinkle E, Sing CF (1987) A cladistic analysis of phenotypic associations with haplotypes inferred from restriction endonuclease mapping. I. Basic theory and an analysis of alcohol dehydrogenase activity in Drosophila. Genetics, 117, 343-351.

Templeton AR, Crandall K, Sing CF (1992) A cladistic analysis of phenotypic associations with haplotypes inferred from restriction endonuclease mapping and DNA sequence data. III Cladogram estimation. Genetics, 132, 619-633.

Templeton AR, Routman E, Phillips CA (1995) Separating population structure from population history: A cladistic analysis of the geographic distribution of mitochondrial DNA haplotypes in the tiger salamander, Ambystoma tigrinum. Genetics, 140, 767-782.

Weider LJ, Hobæk A (2003) Glacial refugia, haplotype distributions, and clonal richness of the Daphnia pulex complex in arctic Canada. Mol. Ecol., 12, 463-473.

Wilke T, Duncan N (2004) Phylogeographical patterns in the American Pacific Northwest: Lessons from the arionid slug Prophysaon coeruleum. Mol. Ecol., 13, 2303-2315.

Wolfe KH, Li WH, Sharp PM (1987) Rates of nucleotide substitution vary greatly among plant mitochondrial, chloroplast and nuclear DNAs. Proc. Nat. Acad. Sci. USA, 84, 9054-9058. 